\title{
Taxocenose de anuros (Amphibia: Anura) em uma área de Floresta Ombrófila Densa no Sul do Brasil
}

\author{
Camila Graziela Armstrong ${ }^{1,3}$ \& Carlos Eduardo Conte $^{2}$ \\ ${ }^{1}$ Guilherme Chiarotti 94, CEP 82640-340, Curitiba, PR, Brasil \\ ${ }^{2}$ Programa de Pós-graduação em Biologia Animal, Universidade Estadual Paulista - UNESP, \\ Rua Cristóvão Colombo 2265, CEP 15054-000, São José do Rio Preto, SP, Brasil \\ ${ }^{3}$ Autor para correspondência: Camila Graziela Armstrong, e-mail: ca_cga@yahoo.com.br
}

\begin{abstract}
ARMStrong, C.G. \& CONTE, C.E. Assemblage of anurans (Amphibia, Anura) of an area of Atlantic Forest, South of Brazil. Biota Neotrop. 10(1): http://www.biotaneotropica.org.br/v10n1/en/ abstract?article+bn00610012010.
\end{abstract}

\begin{abstract}
Assemblage of anurans (Amphibia, Anura) in a locality of dense Atlantic rain forest, Morretes, Paraná, Brazil. The species richness, habitat use and main environmental impacts on a taxocenose of anurans were determined during 19 months, in a region originally covered by dense Atlantic rain forest at Morretes municipality. Thirty-two species of anurans, belonging to ten families, were registered. In the local anuran fauna, $58 \%$ of these species were associated with open areas, and $42 \%$ of the species were associated to forests. Among all species, the most frequently observed reproductive mode was mode 1 - eggs and exotrophic larvae in lentic water, mainly presented by the family Hylidae. The deforestation, which today has the major negative impact on this amphibian assemblage, is present in the region for at least 28 years. Environmental management programs are necessary to keep the diversity of anurans.
\end{abstract}

Keywords: anurans, conservation, inventory, Atlantic Rainforest, environmental impacts.

ARMSTRONG, C.G. \& CONTE, C.E. Taxocenose de anuros (Amphibia: Anura) em uma área de Floresta Ombrófila Densa no Sul do Brasil. Biota Neotrop. 10(1): http://www.biotaneotropica.org.br/v10n1/pt/ abstract?article+bn00610012010.

Resumo: A riqueza de espécies, o uso de habitat e a identificação das principais ameaças sobre uma taxocenose de anfíbios anuros foram determinadas ao longo de 19 meses, em uma localidade originalmente coberta de Floresta Ombrófila Densa no município de Morretes, Paraná, Brasil. Foram registradas 32 espécies de anuros pertencentes a 10 famílias. A anurofauna local apresenta $58 \%$ das espécies associadas à ambientes de área aberta e $42 \%$ associadas à ambientes florestais. Dentre todos os modos reprodutivos registrados, o modo tipo um - ovos e larvas exotróficas em habitats lênticos, foi o mais comum, especialmente em Hylidae. A atividade de desmatamento, que atualmente é umas das causas de maior efeito negativo sobre populações de anfíbios, ocorre a pelo menos 28 anos nessa região. Iniciativas de conservação e o manejo adequado da área são necessários para que a diversidade de anuros possa ser preservada.

Palavras-chave: anuros, conservação, inventário, Floresta Atlântica, impactos ambientais. 


\section{Introdução}

Atualmente o Brasil é o país que abriga a maior diversidade de anfíbios, com 849 espécies (SBH 2009), das quais aproximadamente $61 \%$ são endêmicas (IUCN 2008). Apesar dessa alta diversidade, não há muitos relatos sobre declínios das populações de anfíbios que ocorrem em território brasileiro (Eterovick et al. 2005). Atualmente o Brasil ocupa o quarto lugar em número de espécies de anfíbios ameaçados, tendo uma porcentagem significativamente mais baixa de espécies ameaçadas quando comparada a média mundial (IUCN 2008). Entretanto, é muito provável que o número de espécies ameaçadas no Brasil esteja subestimado, uma vez que a principal causa de declínios e extinções de anfíbios é a destruição de habitats (Fonseca et al. 2008) e o Brasil é atualmente um dos países que mais destroem ou modificam habitats naturais (Lopes 2006). A perda de habitat altera padrões de abundância e diversidade de taxocenoses de anfíbios nas áreas diretamente afetadas, pois resulta na perda de ambientes de reprodução e locais de abrigo e alimentação (Lips et al. 2005).

Dos estudos referentes a declínios de anfíbios no Brasil (ver revisão em Eterovick et al. 2005), a maioria refere-se à Mata Atlântica, um dos "hotspots" de biodiversidade (Myers et al. 2000) que vêm sendo afetado pela perda de habitat, hoje com cerca de $12 \%$ de cobertura original remanescente (Ribeiro et al. 2009).

O rápido declínio de várias espécies de anfíbios ressalta a necessidade de programas de pesquisa para o conhecimento de padrões de diversidade de anfíbios e da implementação de estratégias imediatas para a conservação destas espécies, especialmente em regiões onde existem poucos dados sobre diversidade, abundância e distribuição das espécies (Young et al. 2001). Na Floresta Ombrófila Densa do Estado do Paraná, a maioria dos estudos sobre anfíbios são limitados a descrições de novas espécies, ampliações na distribuição geográfica e alguns resumos divulgados apenas em congressos, com referências pontuais em revisões taxonômicas, dissertações e teses e relatórios técnicos (Silva et al. 2006). Essa carência de informações dificulta a tomada de decisões quanto à conservação das espécies e de seus habitats (Conte \& Machado 2005).

Considerando que o conhecimento da anurofauna associada à Floresta Ombrófila Densa paranaense é muito restrito, neste estudo determinamos a composição taxonômica, modos reprodutivos, o uso de habitats e as principais ameaças sobre uma taxocenose de anfíbios anuros em um remanescente da Floresta Ombrófila Densa paranaense, gerando informações que possam auxiliar na escolha de ações prioritárias para a conservação de espécies de anfíbios no bioma Mata Atlântica.

\section{Material e Métodos}

\section{1. Área de estudo}

O estudo foi desenvolvido na localidade Condomínio Rio Sagrado, (2529' 55” S e 48 50’29”'W) (Figura 1), no Município de Morretes, Paraná, sul do Brasil. Apesar do município de Morretes apresentar áreas bem preservadas em algumas regiões, parte da vegetação da área de estudo encontra-se alterada pela excessiva exploração, principalmente pela especulação imobiliária, cuja invasão maciça da área começou na década de 80 , além do extrativismo de espécies de valor comercial. A partir de 1982 a área total (85,8 ha) foi parcialmente fragmentada com a construção desse Condomínio. Atualmente, a área total do condomínio é de 66 ha, dividida em 110 chácaras, a qual apresenta alguma alteração (e.g. edificações, canalização de água, criação de animais exóticos, plantios de banana) e apenas 19,8 ha de área nativa sem interferência. A região está inserida na zona fitogeográfica Floresta Ombrófila Densa Montana, caracterizada pela predominância de árvores perenifólias de grande porte, associadas principalmente a palmáceas, epífitas e lianas (Roderjan \& Kuniyosshi 1988).

O clima é tropical superúmido, tipo Cfa de Köppen, sem estação de seca e isento de geadas, com temperatura média no mês mais quente superior a $22{ }^{\circ} \mathrm{C}$ e, no mais frio, superior $18{ }^{\circ} \mathrm{C}$ (Ferreira 1996). A precipitação varia de 300 a $1000 \mathrm{~mm}$ mensais, atingindo a média de $2500 \mathrm{~mm}$ anuais, com concentração de chuvas no período de dezembro a março, porém sem estação definida.

\section{Composição, uso do habitat e modos reprodutivos}

Foram realizadas 19 visitas mensais com duração de um dia cada, entre novembro de 2002 e fevereiro de 2004, e de dezembro de 2005 a fevereiro de 2006, totalizando aproximadamente 133 horas de esforço amostral. A cada visita foram empregados dois métodos para amostragem dos anuros: 1) levantamento em sítio de reprodução (sensu Scoot Jr. \& Woodward 1994), efetuado em oito corpos d'água. O perímetro de cada corpo d'água foi percorrido lentamente, sendo registradas as espécies com machos em atividade de vocalização; 2) transecção por busca aural, efetuado em um trecho de $200 \mathrm{~m}$ no interior da floresta, este percorrido lentamente, em linha reta, e registradas as vocalizações de indivíduos distantes de corpos d'água. As amostragens foram realizadas entre 19:00 e 00:00 horas para as espécies noturnas e entre 9:00 e 11:00 horas para as espécies diurnas. O estudo foi desenvolvido em nove ambientes, dentre os quais dois em área aberta, quatro em interior de floresta e três localizados em borda florestal (Tabela 1). Nesse caso a categoria borda foi considerada para os habitats encontrados no limite entre a floresta e área aberta.

A riqueza de espécies na área amostrada foi considerada com base nos registros mensais das espécies, por curva de acumulação de espécies pelo índice "Incidence-based Coverage Estimator" (ICE) (Chao et al. 2006), com 500 repetições aleatórias, calculado pelo programa Estimates 7.5 (Colwell 2005). A identificação das espécies foi feita por comparação direta com exemplares da coleção herpetológica do Museu de História Natural Capão da Imbuia (MHNCI), Curitiba, Paraná e consulta a especialistas. O material testemunho foi depositado na coleção herpetológica do Museu de História Natural Capão da Imbuia (MHNCI, 6513 a 6575). A nomenclatura científica utilizada segue Frost (2009) e Guayasamin et al. (2009).

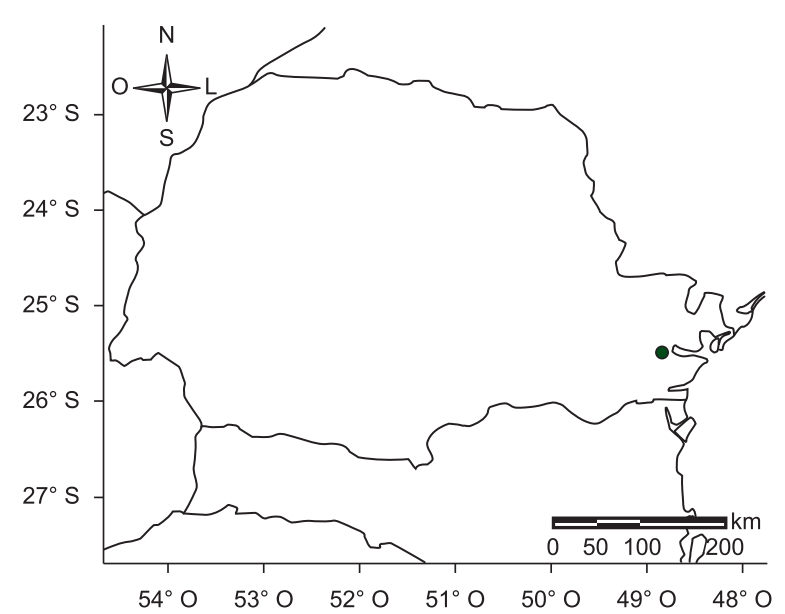

Figura 1. Mapa do estado do Paraná com a localização do município de Morretes, Paraná.

Figure 1. Map of the State of Paraná and the localization of Morretes city, Paraná. 
Anuros da Floresta Ombrófila Densa paranaense

Tabela 1. Principais características dos nove corpos d'água cuja anurofauna foi estuda na localidade Condomínio Rio Sagrado, Morretes, Paraná.

Table 1. Main characteristics of the nine bodies of water whose anurofauna was studies in the locality Condominium Rio Sagrado, Morretes, Paraná.

\begin{tabular}{|c|c|c|c|c|c|}
\hline \multirow{2}{*}{$\frac{\text { Habitats }}{\text { APE }}$} & \multirow{2}{*}{$\begin{array}{c}\text { Velocidade da água } \\
\text { corrente }\end{array}$} & \multicolumn{2}{|c|}{ Vegetação do corpo d'água no interior Marginal } & \multirow{2}{*}{$\begin{array}{l}\text { Vegetaçao local } \\
\text { área aberta }\end{array}$} & \multirow{2}{*}{$\frac{\text { Ação antrópica }}{\text { Sim }}$} \\
\hline & & Ausente & Gra, Her, Arb & & \\
\hline $\mathrm{RB} 1$ & corrente & Esparsa & Her, Arb, Epi, Abo & borda florestal & Sim \\
\hline RB2 & corrente & Esparsa & Her, Arb, Epi, Abo & borda florestal & Sim \\
\hline LAA & parada & Abundante & Gra, Arb & área aberta & Sim \\
\hline $\mathrm{CF} 1$ & corrente & Ausente & Her, Arb, Epi, Abo & floresta & Não \\
\hline RIF & constante troca & Ausente & Her, Arb, Epi, Abo & floresta & Não \\
\hline $\mathrm{CF} 2$ & corrente & Ausente & Her, Arb, Epi, Arb & floresta & Não \\
\hline IFL & ausente & - & Her, Arb, Epi, Arb & floresta & Não \\
\hline PTB & parada & Abundante & Her, Arb, Epi, Arb & borda florestal & Sim \\
\hline
\end{tabular}

Habitats: açude de piscicultura em área aberta (APE), ribeirão 1 em borda florestal (RB1), ribeirão 2 em borda florestal (RB2), lago em área aberta (LAA), córrego 1 em interior de floresta (CF1), córrego 2 em interior de floresta (CF2), rio em interior de floresta (RIF), trecho em interior de floresta (IFL), poça temporária em borda florestal (PTB); tipo de vegetação: Gra = gramínea, Her = herbácea, Arb = arbustiva, Epi = epífitas e Abo = arbórea.

O uso de habitats pelas espécies de anuros, determinado pelo encontro de machos em atividade de vocalização, foi analisado pela aplicação do coeficiente similaridade de Jaccard (Magurran 1988), com posterior análise de agrupamento pelo método de média não ponderada (UPGMA) (Krebs 1999). Os agrupamentos foram definidos pelo valor mínimo de $50 \%$ de similaridade, sendo avaliados pela determinação do Coeficiente de Correlação Cofenética (r) (Romesburg 1984), utilizando-se o programa NTSYS 2.1 (Rohlf 2000). Essa análise avalia a perda de informações na construção dos dendrogramas, sendo considerado um bom ajuste os valores de $r \geq 0,8$.

O modo reprodutivo das espécies registradas foi classificado de acordo, Haddad \& Prado (2005) e Haddad et al. (2008).

\section{Impactos ambientais}

Os impactos ambientais, registrados para a localidade Condomínio Rio Sagrado foram divididos em: 1) quanto ao tipo de desencadeamento que causam na natureza, sendo classificado em escalonado - quando o impacto gera danos de forma progressiva ao ambiente, e imediato - quando o efeito do impacto ambiental é percebido de forma imediata à sua entrada na natureza; 2) quanto à frequiência de ocorrência, sendo classificado em contínuo - quando a presença do impacto ambiental é continuada e sem interrupções, e descontínuo - quando o impacto ambiental ocorre na natureza de forma periódica; 3 ) em extensão, sendo classificado em pontual - quando o impacto ambiental ocorre somente em locais determinados, e espacial - quando o impacto ambiental ocorre em áreas abrangentes sem distinção de áreas pontuais; 4) quanto a possibilidade de reversibilidade pode ser classificado em reversível - se os danos causados pelo impacto ambiental puderem ser revertidos, e irreversível - quando os danos gerados pelo impacto ambiental não puderem ser removidos da natureza; 5) por sua origem, que pode ser medida em anos desde o surgimento do impacto ambiental na natureza; 6) por sua magnitude que pode ser classificada como grande - quando os danos do impacto ambiental causarem grande perda para o meio ambiente, média - quando os danos gerados pelo impacto ambiental causarem perdas medianas ao meio ambiente, e pequena - quando os danos do impacto ambiental gerarem perdas pequenas ao meio ambiente; 7) quanto a importância sendo classificado em moderada - quando a importância e relevância de cada grupo taxonômico e área afetada pelo impacto ambiental for moderada, e grande - quando a relevância dos grupos afetados pelo impacto ambiental for de grande importância para o meio ambiente (Rhode 1988).

\section{Resultados}

\section{Composição, uso do habitat e modos reprodutivos}

Foram registradas 32 espécies de anuros, pertencentes a dez famílias (Tabela 2). Apenas machos de Trachycephalus mesophaeus (Hensel 1867) não foram encontrados em atividade de vocalização. A curva de acumulação de espécies tende a uma assíntota por volta da décima quarta amostra, com o registro de 32 espécies, entretanto a diferença entre o número total de espécies registradas e estimadas é de aproximadamente duas espécies (ICE $\approx 34$ espécies) (Figura 2). $\mathrm{O}$ habitat com maior riqueza de espécies foi o LAA, com a presença de $39 \%$ das espécies registradas para a área de estudo, enquanto que em RIF e CF1 foram registradas apenas 6,5\% das espécies. Machos de Lithobates catesbeianus (Shaw 1802) foram encontrados vocalizando no LAA. O número de habitats utilizados pelas espécies variou de um a quatro, enquanto que o número de espécies que ocorreram num mesmo habitat variou de dois a 10 (Tabela 2).

A análise do uso de habitat pelas espécies evidenciou cinco agrupamentos (Figura 3): 1 - espécies exclusivas de área aberta, que ocorreram somente em habitats de área aberta (AA); 2 - espécies de área aberta/borda, que ocorreram tanto em habitats de área aberta quanto nos de borda florestal (AB); 3 - espécies de borda florestal, que ocorreram somente em habitats de borda florestal (BO); 4 - espécies de floresta/borda, que ocorreram tanto nos habitats florestais quanto nos de borda florestal (FB); 5 - espécies exclusivas de floresta, que ocorreram exclusivamente em habitats no interior de floresta (FL). A anurofauna da área estudada foi constituída, em maior proporção, por espécies associadas à área aberta $(58 \%)$, sendo $26 \%(\mathrm{n}=8)$ exclusivas de AA e $32 \%(n=10)$ exclusivas de AB enquanto que $42 \%$ da anurofauna registrada está associada à floresta, sendo $26 \%$ $(\mathrm{n}=8)$ exclusivas de FL, 10\% $(\mathrm{n}=3)$ exclusivas BO e 6\% $(\mathrm{n}=2)$ exclusiva de FB.

Foram definidos 10 modos reprodutivos para 31 espécies. O modo do tipo 1 (ovos e girinos exotróficos em água parada) foi o mais comum entre as famílias (Tabela 2). A família Hylidae apresentou a maior variedade de modos reprodutivos (61\%), e o modo 1 foi também o mais comum (Tabela 2).

\section{Impactos ambientais}

Com a chegada do primeiro proprietário da área, deu-se origem ao desmatamento a cerca de 28 anos. Os demais impactos registrados para a área são atuantes a pelo menos 10 anos na área de estudo. A maior parte dos impactos ambientais foi classificada como tendo desencadeamento de tipo escalonado $(83 \%)$ e apenas a poluição sonora 
Tabela 2. Espécies de anfíbios anuros registrados nos nove habitats amostrados no Condomínio Rio Sagrado, Morretes, Paraná, no período de novembro de 2002 a fevereiro de 2004 e de dezembro de 2005 a fevereiro de 2006.

Table 2. Species registered of amphibians anurous in nine habitats sampled at Condominium Rio Sagrado, Morretes, Paraná, in the period of November 2002 to the February 2004 and of December 2005 to the February of 2006.

\begin{tabular}{|c|c|c|c|}
\hline Espécie & Habitats & UH & MR \\
\hline \multicolumn{4}{|l|}{ BRACHYCEPHALIDAE } \\
\hline Ischnocnema aff. guentheri & IFL & FL & 23 \\
\hline Ischnocnema sambaqui (Castanho \& Haddad, 2000) & IFL & FL & 23 \\
\hline \multicolumn{4}{|l|}{ BUFONIDAE } \\
\hline Rhinella abei (Baldissera Jr., Caramaschi \& Haddad, 2004) & APE, RB1, RB2, LAA & $\mathrm{AB}$ & 01 \\
\hline Rhinella icterica $($ Spix, 1824$)$ & APE, LAA & AA & 01 \\
\hline \multicolumn{4}{|l|}{ CENTROLENIDAE } \\
\hline Vitreorana uranoscopa (Müller, 1924) & RIF & FL & 25 \\
\hline \multicolumn{4}{|l|}{ CYCLORAMPHIDAE } \\
\hline Proceratophrys boiei (Wied-Neuwied, 1825) & $\mathrm{PTB}, \mathrm{CF} 2$ & FB & 01 \\
\hline \multicolumn{4}{|l|}{ HYLIDAE } \\
\hline Aplastodiscus ehrhardti (Müller, 1924) & $\mathrm{RIF}, \mathrm{CF} 1, \mathrm{CF} 2$ & FL & 05 \\
\hline Bokermannohyla hylax (Heyer, 1985) & RLA, RB2, CF2 & FB & 04 \\
\hline Dendropsophus berthalutzae (Bokermann, 1962) & LAA & AA & 24 \\
\hline Dendropsophus elegans (Wied-Neuwied, 1824) & LAA & AA & 01 \\
\hline Dendropsophus microps (Peters, 1872) & PTB, LAA & $\mathrm{AB}$ & 01 \\
\hline Dendropsophus minutus (Peters, 1872) & APE, PTB, LAA & $\mathrm{AB}$ & 01 \\
\hline Hypsiboas albomarginatus (Spix, 1824) & APE & AA & 01 \\
\hline Hypsiboas bischoff (Boulenger, 1887) & RB1, RB2, PTB & $\mathrm{AB}$ & 01 \\
\hline Hypsiboas faber (Wied-Neuwied, 1821) & APE, LAA & AA & 04 \\
\hline Phyllomedusa distincta B. Lutz, 1950 & APE, PTB & $\mathrm{AB}$ & 24 \\
\hline Scinax aff. alter & LAA & AA & 01 \\
\hline Scinax aff. argyreornatus & $\mathrm{CF} 2$ & FL & 01 \\
\hline Scinax fuscovarius (A. Lutz, 1925) & APE, RB1, RB2, PTB & $\mathrm{AB}$ & 01 \\
\hline Scinax littoralis (Pombal \& Gordo, 1991) & $\mathrm{RB} 2$ & $\mathrm{BO}$ & 01 \\
\hline Scinax perereca Pombal Jr., Haddad \& Kasahara, 1995 & APE, RB1, RB2, PTB & $\mathrm{AB}$ & 01 \\
\hline Scinax aff. perpusillus & IFL & FL & 06 \\
\hline Scinax rizibilis (Bokermann, 1964) & RB1, PTB & $\mathrm{BO}$ & 11 \\
\hline *Trachycephalus mesophaeus (Hensel, 1867) & - & - & 01 \\
\hline \multicolumn{4}{|l|}{ HYLODIDAE } \\
\hline Hylodes heyeri Haddad, Pombal \& Bastos, 1996 & $\mathrm{CF} 1$ & FL & 03 \\
\hline \multicolumn{4}{|l|}{ LEIUPERIDAE } \\
\hline Physalaemus cuvieri Fitzinger, 1826 & PTB, LAA & $\mathrm{AB}$ & 11 \\
\hline Physalaemus cf. olfersii & РTB & $\mathrm{BO}$ & 11 \\
\hline \multicolumn{4}{|l|}{ LEPTODACTYLIDAE } \\
\hline Leptodactylus aff. bokermanni & IFL & FL & - \\
\hline Leptodactylus notoaktites Heyer, 1978 & APE, PTB & $\mathrm{AB}$ & 30 \\
\hline Leptodactylus cf. ocellatus & RB2, LAA & $\mathrm{AB}$ & 11 \\
\hline \multicolumn{4}{|l|}{ MICROHYLIDAE } \\
\hline Elachistocleis bicolor (Guérin-Méneville, 1838) & LAA & AA & 01 \\
\hline \multicolumn{4}{|l|}{ RANIDAE } \\
\hline Lithobates catesbeianus (Shaw, 1802) & LAA & AA & 01 \\
\hline
\end{tabular}

* espécie não encontrada em atividade de vocalização;

Modos reprodutivos utilizados pela anurofauna: (01) ovos e girinos exotróficos em água parada; (02) ovos e girinos exotróficos em água corrente; (03) ovos e estágios larvais iniciais em câmeras sub-aquáticas, girinos exotróficos em córregos; (4) ovos e estágios larvais iniciais em "piscinas" naturais ou construídas, subseqüentes ao enchimento, girinos exotróficos em córregos ou poças; (05) ovos e estágios larvais iniciais em ninho subterrâneos construídos, subseqüente ao enchimento, girinos exotróficos em córregos ou poças; (06) ovos e girinos exotróficos aquáticos em buracos de troncos ou plantas phytotelmatas aéreas; (11) ovos depositados em ninhos de espuma flutuante e girinos exotróficos em poças; (23) desenvolvimento direto de ovos terrestres; (24) ovos arborícolas que eclodem em girinos exotróficos que gotejam em água parada; (25) ovos arborícolas que eclodem em girinos exotróficos que gotejam em água corrente; (30) ninho de espuma com ovos e estágios larvais iniciais em ninhos subterrâneos construídos, subseqüentes ao enchimento, girinos exotróficos em poças - habitats utilizados pelas espécies: açudes de piscicultura em área aberta (APE), ribeirão 1 em borda florestal (RB1), ribeirão 2 em borda florestal (RB2), lago em área aberta (LAA), córrego $1 \mathrm{em}$ interior de floresta (CF1), rio em interior de floresta (RIF), córrego $2 \mathrm{em}$ interior de floresta (CF2), trecho em interior de floresta (IFL), poça temporária em borda florestal (PTB) - classificação das espécies segundo a distribuição no Uso de habitat (UH): FL = espécies florestais estritas, $\mathrm{FB}=$ espécies florestais/borda, $\mathrm{AA}=$ espécies exclusivas de área aberta, $\mathrm{AB}=$ espécies de área aberta/borda e $\mathrm{BO}=$ espécies de borda florestal. 


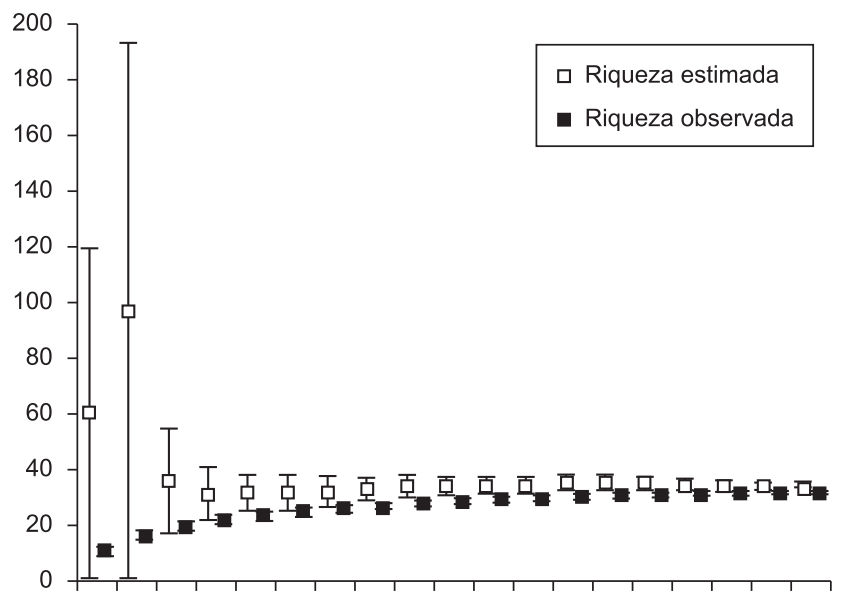

nov/02 jan/02 mar/03 mai/03 jul/03 set/03 nov/03 jan/04 dez/05 fev/06

Figura 2. Curva de acumulação de espécies, baseada na ocorrência mensal de anuros, registrados nos nove habitats amostrados no Condomínio Rio Sagrado, Morretes, Paraná, no período de novembro de 2002 a fevereiro de 2004 e de dezembro de 2005 a fevereiro de 2006 (intervalo de confiança $95 \%$ )

Figure 2. Accumulation curve of the species, based on the monthly occurrence of anurans, recorde in nine habitats sampled at Condominium Rio Sagrado, Morretes, Paraná, in the period of November of 2002 to the February of 2004 and of December 2005 to the February of 2006 (95\% confidence interval lower and upper bounds).

foi classificada como imediato. Todos os impactos ambientais foram classificados como reversíveis e a maior parte foi considerada de grande importância (66\%) e magnitude (66\%) para a área de estudo. Cerca de $66 \%$ dos impactos ambientais afetam uma grande extensão da área de estudo, sendo classificados como impactos espaciais, e na maioria das vezes apresentam freqüência contínua. Foram considerados como de maior importância para a taxocenose de anfíbios o desmatamento, o lançamento de efluentes, o desvio de cursos d'água e o empobrecimento do solo, todos com frequiência contínua, extensão espacial e grande magnitude (Tabela 3).

\section{Discussão}

\section{Composição, uso do habitat e modos reprodutivos}

As 32 espécies registradas na área de estudo correspondem a 26\% das espécies de anfíbios conhecidas para o Estado do Paraná (Mikich et al. 2004), sendo similar ao número total de espécies encontradas em outras localidades inventariadas nesse estado (ver revisão em Conte \& Rossa-Feres 2006). Entretanto, o número de espécies registradas corresponde a $94 \%$ da riqueza estimada, prevendo um pequeno aumento do número de espécies na área.

A maioria das espécies foi associada à área aberta e podem ser divididas em três grupos: 1) espécies que ocorrem em ambientes de baixada em área aberta ou de ocorrência em bordas e clareiras (D. berthalutzae, D. elegans, D. microps, H. albomarginatus e Scinax aff. alter - Izecksohn \& Carvalho-e-Silva 2001); 2) espécies florestais que se reproduzem em áreas abertas e/ou generalistas (R. abei, D. minutus, H. bischoffi, H. faber, S. perereca, P. distincta, L. notoaktites - Haddad 1998, Bertoluci \& Rodrigues 2002, Conte \& Rossa-Feres 2007, C.E. Conte, obs. pess.); 3) espécies resistentes a alterações ambientais de origem antrópica, comumente encontradas em locais periantrópicos (R. icterica, S. fuscovarius, L. ocellatus, E. bicolor - Feio et al. 1998, Machado et al. 1999,

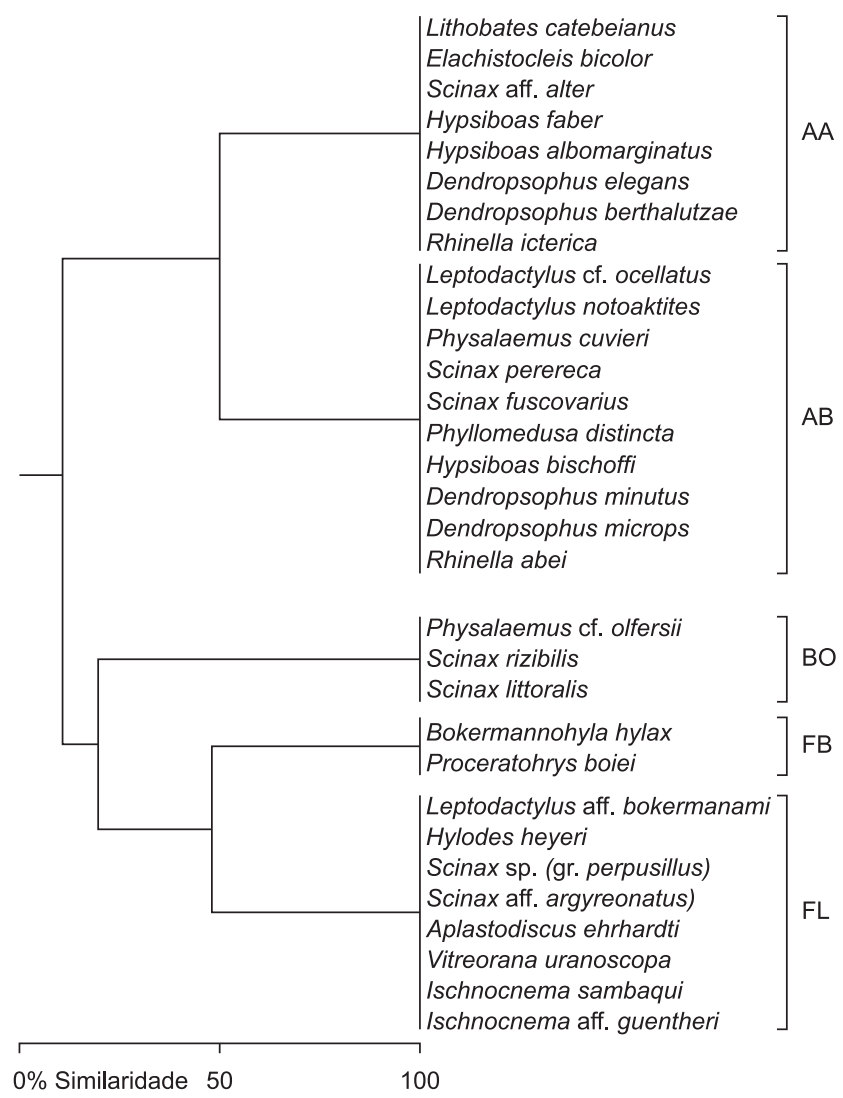

Figura 3. Similaridade (\%) no uso de habitat entre as 31 espécies registradas em atividade de vocalização nos nove habitats amostrados no Condomínio Rio Sagrado, Morretes, Paraná, no período de novembro de 2002 a fevereiro de 2004 e de dezembro de 2005 a fevereiro de 2006. AA = espécies exclusivas de área aberta, $\mathrm{AB}=$ espécies de área aberta/borda, $\mathrm{BO}$ = espécies exclusivas de borda de florestal, FB = espécies de floresta/borda, FL = espécies exclusivas de floresta. Coeficiente de correlação cofenético $=0,94$.

Figure 3. Similarity $(\%)$ in the habitat use between the 31 anuran species recorded in activity of vocalization in nine habitats sampled at Condominium Rio Sagrado, Morretes, Paraná, in the period of November 2002 to the February 2004 and of December 2005 to the February 2006. AA = exclusive species of open area, $\mathrm{AB}=$ species of open area/edge, $\mathrm{BO}=$ exclusive species of edge of forest, $\mathrm{FB}=$ species of forest/edge, $\mathrm{FL}=$ exclusive species of forest. Cophenetic coefficient of correlation $=0,94$.

Izecksohn \& Carvalho-e-Silva 2001, Eterovick \& Sazima 2004, Ramos \& Gasparini 2004). Essas espécies podem ser consideradas sinantrópicas, uma vez que se beneficiam de modificações antrópicas do ambiente que disponibilizam novas áreas para reprodução (e.g. açudes de piscicultura, poças e lagos). Como essas espécies não necessitam de recursos especializados para reprodução, elas são mais tolerantes a alterações ambientais e, desse modo, podem ampliar sua distribuição (Haddad 1998).

Durante o estudo observamos a dispersão da espécie exótica invasora L catesbeianus. Ao longo do primeiro período de coleta de dados (novembro de 2002 e fevereiro de 2004) a espécie foi observada em um açude em área aberta, localizado a 1,5 km de distância dos habitats amostrados. Já no segundo período de amostragem (dezembro de 2005 a fevereiro de 2006), foram encontrados dezenas de indivíduos vocalizando no LAA. No Estado do Paraná, a espécie já foi registrada em Telêmaco Borba (Rocha et al. 2003), São José dos Pinhais (Conte \& Rossa-Feres 2006), Curitiba, Fazenda Rio Grande e Guarapuava (C.E. Conte, dados não publicados). Além do Estado do Paraná, existem registros de 
Armstrong, C.G. \& Conte, C.E.

Tabela 3. Caracterização dos impactos ambientais, registrados na localidade do Condomínio Rio Sagrado, Morretes, Paraná.

Table 3. Characterization of the environmental impacts, recorded at Condominium Rio Sagrado locality, municipality of Morretes, Paraná State.

\begin{tabular}{|c|c|c|c|c|c|c|}
\hline Impactos & DS & PS & $\mathbf{L E}$ & $\mathbf{Q L}$ & DC & ES \\
\hline Desencadeamento & escalonado & imediato & escalonado & escalonado & escalonado & escalonado \\
\hline Frequência & continua & descontínua & contínua & descontínua & continua & contínua \\
\hline Extensão & espacial & pontual & espacial & pontual & espacial & espacial \\
\hline Reversibilidade & reversível & reversível & reversível & reversível & reversível & reversível \\
\hline Origem & 16 & 10 & 10 & 10 & 10 & 10 \\
\hline Magnitude & grande & pequena & grande & média & grande & grande \\
\hline Importância & grande & moderada & grande & moderada & grande & grande \\
\hline
\end{tabular}

Impactos ambientais: DS = desmatamento, PS = poluição sonora, LE = lançamento de efluentes, QL = queima de lixo, DC = desvio de cursos d'água,

ES = empobrecimento do solo; classificação: desencadeamento = escalonado/imediato, freqüência = contínua/descontínua, extensão = pontual/espacial,

reversibilidade $=$ reversível/irreversível, origem $=$ tempo atuante na área em anos, magnitude $=$ pequena/média/grande, $\mathrm{importância}=\mathrm{moderada} /$ grande .

populações livres principalmente nas regiões Sudeste e Sul do Brasil (Vizotto 1984, Guix 1990, Costa et al. 1998, Borges-Martins et al. 2002, Sasso-Cerri et al. 2004). Esta espécie apresenta uma grande capacidade de adaptação aos diferentes regimes climáticos brasileiros (Instituto Hórus 2005), e o principal impacto dessa espécie é a competição com anuros nativos (Hayes \& Jennings 1985). Segundo Batista (2002), em uma comunidade de anuros em Goiás, após a introdução de L. catesbeianus ocorreu um aparente desaparecimento de Leptodactylus ocellatus e L. labirinthycus (Spix, 1824).

Dos 39 modos reprodutivos conhecidos para os anfíbios anuros, 27 ocorrem na Mata Atlântica, sendo oito exclusivos deste bioma (Haddad \& Prado 2005). O modo reprodutivo do tipo 1 (desova em ambientes lênticos) foi considerado o mais freqüente entre a anurofauna da área de estudo, sendo também o mais comum entre os anfíbios (Haddad \& Prado 2005). O registro de um elevado número de espécies que se reproduzem pelo modo do tipo 1 também foi observado para outras regiões da Floresta Atlântica, por exemplo: $50 \%$ na Serra do Japi (Haddad \& Sazima 1992), 50\% no Parque Estadual de Intervales (Bertoluci 2001), 50\% no Parque Estadual Mata dos Godoy (Bernarde \& Anjos 1999), 52,6\% na Fazenda São Luis, Ribeirão Branco/Apiaí (Pombal Jr. \& Haddad 2005), 52\% na Floresta Estadual Edmundo Navarro de Andrade, Rio Claro (Toledo et al. 2003), 54\% em Tijucas do Sul (Conte \& Machado 2005), 55\% na Fazenda Gralha Azul, Fazenda Rio Grande (Conte \& Rossa-Feres 2007) e 52\% na Mata São José, Rio Claro (Zina et al. 2007). Em locais que apresentam sazonalidade acentuada e paisagem extremamente antropizada tendem a apresentar um maior número de espécies com este modo reprodutivo, como por exemplo: 64\% em Guararapes (Bernarde \& Kokubum 1999), 59\% em Nova Itapirema (Vasconcelos \& Rossa-Feres 2005), 60\% em Santa Fé do Sul, (Santos et al. 2007) e 64\% em Icém (Silva \& Rossa-Feres 2007). Segundo Hödl (1990), fatores ambientais, como a alta umidade e temperatura, além de ausência de sazonalidade são importantes para evolução de modos reprodutivos especializados. Espécies características de área aberta apresentam modos reprodutivos mais generalizados ou especializados para permitir a reprodução em áreas sujeitas à secas sazonais, alta luminosidade, e baixa heterogeneidade ambiental (Prado et al. 2005, Santos et al. 2008), como modos reprodutivos associados a ninhos de espuma e tocas subterrâneas. Na anurofauna do Condomínio Rio Sagrado, das 18 espécies associadas à área aberta, 83\% apresentaram modos reprodutivos mais generalizados e especializados a secas sazonais (66\% modo $1,11 \%$ modo 11 e $6 \%$ modo 30 ) e apenas $17 \%$ $(\mathrm{n}=3)$ dessas espécies apresentaram modos especializados (modos 4 e 24$)$.

Ao contrário das espécies associadas à área aberta, apenas $42 \%$ dos anuros estão associados à floresta e apresentaram modos gene- ralizados e/ou especializados a secas sazonais (23\% modo um e $15 \%$ modo 11). Os modos reprodutivos mais especializados (modos $3,5,6$, 23 e 25), foram típicos de espécies florestais. As florestas litorâneas, associadas com a alta incidência de chuvas, dispõem de um grande número de microambientes que possibilita a especialização reprodutiva tanto para sítios de oviposição quanto para sítios de vocalização. O modo reprodutivo especializado de algumas espécies florestais pode restringir a sua ocorrência devido à ausência de microambientes necessários para a reprodução em áreas abertas.

Apesar da maioria das espécies possuírem associação a áreas abertas, as espécies associadas à habitats florestais representam $42 \%$ da anurofauna local e dessas $25 \%$ são registradas apenas em habitats de interior de floresta, com vegetação bem preservada, apresentando, desse modo, caráter estenóico. A perda ou descaracterização do habitat afeta principalmente as espécies estenóicas que dependem da maior umidade encontrada em ambientes florestais (Leptodactylus aff. bokermanni, I. aff. guentheri, I. sambaqui); da densa vegetação epifítica, típica de florestas preservadas (Scinax aff. perpusillus); ou dependentes de rios e/ou córregos pedregosos com densa cobertura florestal (A. ehrhardti, H. heyeri, V. uranoscopa), necessários para a sobrevivência e desenvolvimento dos girinos destas espécies. Além disso, a retirada da vegetação nas margens de córregos e poças pode interferir na reprodução de espécies que utilizam a vegetação marginal como sítio reprodutivo ( $S$. aff. argyreornatus).

\section{Impactos ambientais}

Dos impactos ambientais diagnosticados para o Condomínio Rio Sagrado, os que podem ter maior impacto sobre a anurofauna local é o lançamento de efluentes poluídos, pois altera a qualidade dos cursos d'água utilizados pelos anuros para a reprodução e o corte de árvores, que permite a entrada de ventos e o aumento da luminosidade o que pode influenciar na umidade florestal, afetando espécies que ocorrem no chão úmido de floresta. Estes impactos atuam diretamente nos habitats APE, RB1, RB2, LAA e PTB. Já os habitats RIF, CF1, CF2 e IFL estão inseridos no remanescente florestal preservado caracterizado por não sofrer diretamente modificações causadas pela ação humana. O principal impacto ambiental sobre as espécies que dependem desses habitats é o carreamento de efluentes, que pode atuar negativamente sobre a reprodução e o desenvolvimento das desovas e sobre o habitat.

O município de Morretes está localizado em área de proteção ambiental (APA) de Mata Atlântica, que apresenta um regime especial de exploração por meio de técnicas de manejo que garantam a estabilidade e perpetuidade deste ecossistema, obedecendo aos critérios da legislação federal e estadual e as normas específicas estabelecidas pelo Poder Executivo (Lei Florestal Paranaense no 11054 de 11/01/1995). Entretanto, o sistema de preservação dos ambientes no Condomínio 
Rio Sagrado é deficiente, sendo freqüente o descaso dos moradores com a legislação ambiental. A especulação imobiliária na localidade leva a construção desordenada de chácaras para o lazer de veranistas que se beneficiam da falta de fiscalização para o uso indevido dos recursos naturais dessa localidade promovendo o desmatamento irregular de áreas para construção de chácaras e plantios, o desvio cursos d'água para a utilização dentro das chácaras, o lançamento de esgoto direto no curso do rio e realizando queimadas de lixo ou enterrando o mesmo não dando um destino final adequado ao lixo doméstico.

O Condomínio Rio Sagrado está inserido na planície litorânea e apresenta $21 \%$ da anurofauna típica do bioma da Floresta Ombrófila Densa (B. hylax, D. berthaluzae, D. elegans, S. aff. alter, S. aff. argyreornatus, S. littoralis, Scinax aff. perpusillus) (IUCN 2008). Desse modo, se faz necessário o aumento de estudos anurofaunísticos na Floresta Ombrófila Densa paranaense, que embora detenha uma das maiores e mais bem preservadas áreas de remanescentes dessa sub-formação (Fundação SOS Mata Atlântica et al. 1998), sofre continuamente com o desmatamento, gerando distribuições dijuntas, que podem, por sua vez, resultar em declínios populacionais e extinções de espécies (Silvano et al. 2003).

\section{Agradecimentos}

Ao Fausto Nomura, Janael Ricetti, Paulo Bernarde e Reginaldo A. Machado pelas críticas e contribuições na versão preliminar. Aos moradores do condomínio Rio Sagrado pela concessão da área de estudo. A Cláudia Guimarães e Rafael Gomes pelo auxílio nas atividades de campo.

\section{Referências}

BATISTA, C.G. 2002. Rana catesbeiana (bullfrog). Effects on native anuran community. Herpetol. Rev. 33:131.

BERNARDE, P.S. \& ANJOS, L. 1999. Distribuição espacial e temporal da Anurofauna do Parque Estadual Mata dos Godoy, Londrina, Paraná, Brasil (Amphibia, Anura). Comun. Mus. Ciênc. Tecnol. 12:127-140.

BERNARDE, P.S. \& KOKUBUM, M.N.C. 1999. Anurofauna do Município de Guararapes, Estado de São Paulo, Brasil (Amphibia, Anura). Acta Biol. Leopoldensia 21(1):89-97.

BERTOLUCI, J.A. 2001. Anfíbios anuros. In Intervales: fundação para a conservação e a produção florestal do Estado de São Paulo (C. Leonel, ed.). Secretaria do Estado de São Paulo, São Paulo, p. 157-167.

BERTOLUCI, J. \& RODRIGUES, M.T. 2002. Seasonal patterns of breeding activity of Atlantic Rainforest anurans at Boracéia, Southeastern Brazil. Amphib-Reptilia 23(2): 161-167.

BORGES-MARTINS, M., DI-BERNARDO, M., VINCIPROVA, G. \& MEASEY, J. 2002. Geographic distribution. Rana catesbeiana. Herpetol. Rev. 33(4):319.

CHAO, A., CHAZDON, R.L., COLWELL, R.K. \& SHEN, T. 2006. Abundance-based similarity indices and their estimation when there are unseen species in samples. Biometrics 62(2):361-371.

COLWELL, R.K. 2005. Estimates: statistical estimation of species richness and shared species from samples. Version 7.5. University of Connecticut, Storrs. http://viceroy.eeb.uconn.edu/estimates (último acesso em 01/12/2009)

CONTE, C.E. \& MACHADO, R.A. 2005. Riqueza de espécies e distribuição espacial e temporal em comunidade de anfíbios anuros (Amphibia, Anura) em uma localidade do Município de Tijucas do Sul, Paraná, Brasil. Rev. Bras. Zool. 22(4):940-948.

CONTE, C.E. \& ROSSA-FERES, D.C. 2006. Diversidade e ocorrência temporal da anurofauna (Amphibia, Anura) em São José dos Pinhais, Paraná, Brasil. Rev. Bras. Zool. 23(1):162-175.
CONTE, C.E. \& ROSSA-FERES, D.C. 2007. Riqueza e distribuição espaçotemporal de anuros em um remanescente de Floresta de Araucária no sudeste do Paraná. Rev. Bras. Zool. 24(4):1025-1037.

COSTA, L.S.C., LIMA, S.I., ANDRADE, D.R. \& AGOSTINHO, C.A. 1998. Caracterização morfológica dos estádios de desenvolvimento de aparelho reprodutor masculino da rã-touro, Rana catesbeiana, no sistema anfigranja de criação intensiva. Rev. Bras. Zool. Tec. 27:651-657.

ETEROVICK, P.C. \& SAZIMA, I. 2004. Anfíbios da Serra do Cipó - Minas Gerais, Brasil - Amphibians from the Serra do Cipó. Ed. PUC Minas, Belo Horizonte.

ETEROVICK, P.C., CARNAVAL, A.C.O.Q., BORGES-NOJOSA, D.M., SILVANO, D.L., SEGALLA, M.V. \& SAZIMA, I. 2005. Amphibian declines in Brazil: an overview. Biotropica 37(2):166-179.

FEIO, R.N., BRAGA, U.L.M., WIEDERHECKER, H. \& SANTOS, P.S. 1998. Anfíbios do Parque Estadual do Rio Doce (Minas Gerais). Universidade Federal de Viçosa, Minas Gerais.

FERREIRA, J.V.C. 1996. O Paraná e seus municípios. Ed. Memória brasileira, Maringá.

FONSECA, C.R., BECKER, C.G., HADDAD, C.F.B. \& PRADO, P.I. 2008. Metamorfose: o declínio mundial dos anfíbios é agravado pela desconexão entre o hábitat aquático dos girinos e o hábitat terrestre dos adultos, induzida pelas atividades humanas. Sci. Am. 72:88-93.

FROST, D.R. 2009. Amphibian Species of the World: an online reference. Version 3.0. New York. http://research.amnh.org/herpetology/amphibia/ index.html (último acesso em 21/11/2009).

FUNDAÇÃO SOS MATA ATLÂNTICA, INSTITUTO NACIONAL DE PESQUISAS ESPACIAIS \& INSTITUTO SÓCIO AMBIENTAL. 1998. Atlas da Evolução dos remanescentes florestais e ecossistemas associados do domínio da Mata Atlântica durante o período de 19901995. São Paulo.

GUAYASAMIN, J.M., CASTROVIEJO-FISHER, S., TRUEB, L., AYARZAGÜENA, J., RADA, M. \& VILÀ, C. 2009. Phylogenetic systematics of Glassfrogs (Amphibia: Centrolenidae) and their sister taxon Allophryne ruthveni. Zootaxa 2100:1-97.

GUIX, J.C. 1990. Introdução e colonização de Rana catesbeiana Shaw, 1802, em um pequeno vale no município de Suzano (SP), sudeste do Brasil. Grupo Estud. Ecol. Sér. Doc. 2:32-34.

HADDAD, C.F.B. 1998. Biodiversidade dos anfíbios no Estado de São Paulo. In Biodiversidade do Estado de São Paulo, Brasil: síntese do conhecimento ao final do século XX (R.M.C. Castro, ed.). Ed. FAPESP, São Paulo, p. 17-26. (v. 6)

HADDAD, C.F.B. \& SAZIMA, I. 1992. Anfíbios Anuros da Serra do Japi. In História Natural da Serra do Japi: ecologia e preservação de uma área florestal no Sudeste do Brasil (L.P.C. Morellato, ed.). UNICAMP, Campinas, p. 188-211.

HADDAD, C.F.B. \& PRADO, C.P.A. 2005. Reproductive modes in frogs and their unexpected diversity in the Atlantic Forest of Brazil. BioScience 55(3):207-217.

HADDAD, C.F.B., TOLEDO, L.F. \& PRADO, C.P.A. 2008. Anfíbios da Mata Atlântica: guia dos anfíbios anuros da Mata Atlântica. Ed. Neotropica, São Paulo.

HAYES, M.P. \& JENNINGS, M.R. 1985. Decline of ranid frog species in western North America: are bulfrogs (Rana catesbeiana) responsible? J. Herpetol. 20:490-509.

HÖDL, W. 1990. An analysis of foam nest construction in the neotropical frog Physalaemus ephippifer. Copeia 2:547-554.

INSTITUTO HÓRUS DE DESENVOLVIMENTO E CONSERVAÇÃO AMBIENTAL. 2008. Espécies exóticas invasoras: fichas técnicas. Florianópolis, SC. http://www.institutohorus.org.br (último acesso em 12/07/2008).

INTERNATIONAL UNION FOR CONSERVATION OF NATURE. 2008. Conservation International \& Nature Serve. Global Amphibian Assessment. http://www.globalamphibians.org (último acesso em 03/03/2009). 
IZECKSOHN, E. \& SILVA, S.P.C. 2001. Anfíbios do município do Rio de Janeiro. Ed. UFRJ, Rio de Janeiro.

KREBS, C.J. 1999. Ecological methodology. Addison-Wesley Educational Publishers, California.

LIPS, K.R., BURROWES, P.A., MENDELSON, J.R. \& PARRA-OLEA, G. 2005. Amphibian population declines in Latin America: a synthesis. Biotropica 37(2):222-226.

LOPES, J.S.L. 2006. Sobre processos de "ambientalização" dos conflitos e sobre dilemas da participação. Horizontes antropológicos. 12(25):3164.

MACHADO, R.A., BERNARDE, P.S., MORATO, S.A.A., ANJOS, L. 1999. Análise comparada da riqueza de anuros entre duas áreas com diferentes estados de conservação no Município de Londrina, Paraná, Brasil (Amphibia, Anura). Rev. Bras. Zool. 16(4): 997-1004.

MAGURRAN, A. 1988. Ecological diversity and its measurement. Princeton University Press, Princeton.

MIKICH, S.B., SILVA, S.M. \& BRITTO, M.M. 2004. O projeto Malha Florestal e o papel das unidades de conservação na manutenção da Floresta Estacional Semidecidual do Estado do Paraná, Brasil. In Anais IV Congresso Brasileiro de Unidades de Conservação (M.S. Milano, L.Y. Takahashi, \& M.L. Nunes, eds). Instituto ambiental do Paraná, Curitiba, p. 260-270. (v. 1)

MYERS, N., MITTERMEIER, R.A., MITTERMEIER, C.G., FONSECA, G.A.B. \& KENT, J. 2000. Biodiversity hotspots for conservation priorities. Nature. 403:853-858.

POMBAL Jr., J.P. \& HADDAD, C.F.B. 2005. Estratégias e modos reprodutivos de anuros (Amphibia) em uma poça permanente na Serra de Paranapiacaba, sudeste do Brasil. Pap. Avulsos Zool. 45(15):201-213.

PRADO, C.A., UETANABARO, M. \& HADDAD, C.F.B. 2005. Breeding activity patterns, reproductive modes, and habitat use by anurans (Amphibia) in a seasonal environment in the Pantanal, Brazil. AmphibReptilia. 26:211-221.

RAMOS, D.A. \& GASPARINI, J.L. 2004. Anfíbios do Goiapaba-Açu. Fundão, Estado do Espírito Santo. Gráfica Santo Antônio, Espírito Santo.

RHODE, G.M. 1988. Estudo de impacto ambiental. Ed. CIENTEC, Porto Alegre.

RIBEIRO, M.C., METZGER, J.P., MARTENSEN, A.C., PONZONI, F.J. \& HIROTA, M.M. 2009. The Brazilian Atlantic Forest: how much is left, and how is the remaining forest distributed? Implications for conservation. Biol. Conserv. 142(6):1144-1156.

RODERJAN, C.T. \& KUNIYOSHI, Y.S. 1988. Macrozoneamento florístico da Área de Proteção Ambiental de Guaraqueçaba. FUPEF, Curitiba, 53 p. (Série Técnica n. 15)

ROHLF, F.J. 2000. NTSYS 2.1: Numerical Taxonomic and Multivariate Analysis System. Exeter Software, New York.

ROMESBURG, H.C. 1984. Cluster analysis for researches. Robert E. Krieger Publishing Company, Florida.

SANTOS, T.G., ROSSA-FERES, D.C. \& CASATTI, L. 2007. Diversidade e distribuição espaço-temporal de anuros em região com pronunciada estação seca no sudeste do Brasil. Iheringia, Sér. Zool. 97(1): 37-49.
SANTOS, T.G., KOPP, K., SPIES, M.R., TREVISAN, R. \& CECHIN, S.Z. 2008. Distribuição temporal e espacial de anuros em área de Pampa, Santa Maria, RS. Iheringia, Sér. Zool. 98(2):244-253.

SASSO-CERRI, E., FARIA, F.P., FREYMÜLLER, E. \& MIRAGLIA, S.M. 2004. Testicular morphological changes during the seasonal reproductive cycle in the Bullfrog Rana catesbeiana. J. Exp. Zool. 301A(3):249-260.

SOCIEDADE BRASILEIRA DE HERPETOLOGIA. 2009. Lista de espécies de anfíbios do Brasil. São Paulo. http://www.sbherpetologia.org.br/ checklist/anfibios.htm. (último acesso em 02/02/2009).

SCOOT JR, N.J. \& WOODWARD, B.D. 1994. Survey at breeding sites. In Measuring and monitoring biological diversity - standard methods for amphibians (W.R. Heyer, M.A. Donnelly, R.W. Mcdiarmid \& M.S. Foster, eds). Smithsonian Institute Press, Washington, p. 118-125.

SILVA, M.O., MACHADO, R.A. \& GRAF, V. 2006. O conhecimento de Amphibia do Estado do Paraná. In Revisões em Zoologia I: volume comemorativo dos 30 anos do Curso de Pós-Graduação em Zoologia da Universidade Federal do Paraná (E.L.A. Monteiro-Filho \& J.M.R. Aranha, orgs). M5 Gráfica e Editora, Curitiba, p. 305-314.

SILVA, F.R. \& ROSSA-FERES, D.C. 2007. Uso de fragmentos florestais por anuros (Amphibia) de área aberta na região noroeste do Estado de São Paulo. Biota Neotrop. 7: (1-7):http://www.biotaneotropica.org.br/v7n2/ pt/abstract?article+bn03707022007 (último acesso em 22/04/2009).

SILVANO, D.L., COLLI, G.R., DIXO, M.B. DE O., PIMENTA, B.V.S. \& WIEDERHECKER, H.C. 2003. Anfíbios e Répteis. In Fragmentação de Ecossistemas: causas, efeitos sobre a biodiversidade e recomendações de políticas públicas (D.M. Rambaldi \& D.A.S. Oliveira, eds). Ministério do Meio Ambiente, Brasília, p. 183-200.

TOLEDO, L.F., ZINA, J. \& HADDAD, C.F.B. 2003. Distribuição espacial e temporal de uma comunidade de anfíbios do Município de Rio Claro, São Paulo, Brasil. Holos Environment. 3(2):136-149.

VASCONCELOS, T.S. \& ROSSA-FERES, D.C. 2005. Diversidade, distribuição espacial e temporal de anfíbios anuros (Amphibia, Anura) na região noroeste do Estado de São Paulo, Brasil. Biota Neotrop. 5(2): http:// www.biotaneotropica.org.br/v5n2/pt/abstract?article+BN01705022005 (último acesso em 19/06/2009).

VIZOTTO, L.D. 1984. Ranicultura. Cienc. Cult., 36(1):42-45.

YOUNG, B.E., LIPS, K.R., REASER, J.K., IBÁÑEZ, R., SALAS, A.W., CEDEÑO, J.R., COLOMA, L.A., RON, S., MARCA, E. LA, MEYER, J.R., MUÑOZ, A., BOLAÑOS, F., CHAVES, G. \& ROMO, D. 2001. Population declines and priorities for Amphibian conservation in Latin America. Conserv Biol. 15(5):1213-1223.

ZINA, J., ENNSER, J., PINHEIRO, S.C.P., HADDAD, C.F.B. \& TOLEDO, L.F. 2007. Taxocenose de anuros de uma mata semidecídua do interior do Estado de São Paulo e comparações com outras taxocenoses do Estado, Brasil. Biota Neotrop. 7(2): http://www.biotaneotropica.org.br/v7n2/pt/ abstract?article+bn00607022007 (último acesso em 22/09/2008).

Recebido em 24/06/09 Versão reformulada recebida em 16/11/09 Publicado em 5/01/10 